\title{
PRODUCTIVITY IN UK HEALTHCARE DURING AND AFTER THE COVID-19 PANDEMIC
}

\author{
Diane Coyle $^{1 \star}$, Kaya Dreesbeimdiek ${ }^{2}$ and Annabel Manley ${ }^{1}$ \\ ${ }^{1}$ Bennett Institute, University of Cambridge, Cambridge, United Kingdom \\ ${ }^{2}$ Department of Engineering, University of Cambridge, Cambridge, United Kingdom \\ *Corresponding author. Email: dc700@cam.ac.uk
}

Measured health output in the UK declined sharply during the Covid-19 pandemic, despite the evident large increase in some National Health Service (NHS) activities such as critical care, and the new test and trace and vaccination programmes. We explain the measurement methods applied to public services that produced the published decline, in the context of the inherent difficulties of defining and measuring health output and productivity; and describe the changes in practice that had to take place in NHS hospitals. We also discuss, on the basis of these changes including increased use of technology, the likely outlook for healthcare productivity. We conclude that within NHS England capacity, constraints have contributed to substantial falls in non-Covid-19 healthcare output and argue that increased capacity in the social infrastructure of the health service is essential to enable higher productivity in an uncertain environment.

Keywords: productivity; healthcare; social infrastructure.

JEL codes: H51; I10; E01.

\section{Introduction}

Tracking economic activity during the pandemic has been challenging, and nowhere more so than in the measurement of the output and productivity of the health sector as it came under intense pressure. A sharp fall in volume-terms public sector output, with health services making up 37.5 per cent of the total public expenditure (and 10 per cent of GDP in 2018), contributed to the UK's plunge in GDP in the second quarter of 2020. This contrasted with the profile of the public sector contribution to growth in some other European economies. This paper explains the reasons for this sharp decline in measured UK health service output and productivity, in the context of the inherent challenges of public service productivity measurement, and considers the longer-term prospects for health productivity improvements.

First, we discuss the measurement method used in the UK, explaining why the health output measure in the national accounts declined so sharply when, after all, some health services were extremely busy. We also discuss the implications for the separate UK health service productivity measures, which are not incorporated in the output and GDP statistics.

However, the decline in health service output cannot be considered to be a mere statistical quirk, although measurement has been challenging. The pressure the crisis placed on the National Health Service (NHS) led to significant changes in service provision during the year and will have some lasting positive and negative effects on output and productivity. The crisis has led to changes in organisation and the use of technology. At the same time, there was a large decline in non-Covid-19 service provision of all kinds, leading to a major backlog of treatments. This consequence of limited NHS capacity-due to continuing pressures over many years to seek efficiencies and meet centrally determined targets-raises 
the question of the option value of 'spare' capacity and the need for insurance against future pandemics or crises.

It is also important to note that output and productivity measurement is distinct from an evaluation of health outcomes and economic welfare. Health outcomes during the pandemic have been better than they would have been had the NHS not dramatically changed its mix of activities, while the final assessment of outcomes will bring in wider and complex considerations such as life years lost from delayed or cancelled procedures as well as Covid-19 lives saved.

We explore the short- and long-term implications of the pandemic for health service output and productivity, first reporting insights from qualitative interviews with senior clinical leaders (conducted in November and December 2020) in two English hospital trusts. We describe what happened in these hospitals during the pandemic and discuss which changes they made (such as use of technology or organisational changes) might continue. These experiences underline other evidence of underlying issues not only regarding health service productivity, but also health outcomes relating to NHS provision.

We conclude by considering the lessons of the pandemic experience for service resilience, and the consequences for resourcing and managing the health service. We conclude by arguing the consideration of health services as a key component of the UK's social infrastructure, implying a need for sufficient additional capacity for peak loads. The emphasis on short-term cost efficiency has militated against having a capacity margin with option value that would have limited the output fall during the pandemic, but more importantly would also have led to improved health outcomes compared to those the UK will experience, and thus improved productivity potential over the longer term. For productivity to be a useful concept in the face of uncertain future shocks, it should not ignore the expected value of output in a wide range of circumstance.

\section{Measurement of health service output and productivity}

Total UK government expenditure on health has increased significantly during the pandemic, amounting to an additional $£ 50$ bn for the NHS for Covid-19 response in NHS Confederation, 2020. However, the measurement of public sector output including health in volume terms, and consequently the productivity of public services, has always been challenging because there are no market prices with which to deflate expenditure.

For many years, the convention everywhere was to assume the value of outputs was the same as the value of inputs. Yet, even when all statistical offices were using this same straightforward methodology, comparisons across countries have never been straightforward because the mix of public and private provision differs. These range from largely public in the UK through the NHS to largely private in the United States. Over time, the methodological practices have diverged too (Schreyer and Mas, 2018), with the Office for National Statistics (ONS) having gone further than most others in adopting direct measures of outputs for use in the national accounts, ${ }^{1}$ and in developing quality-adjusted output for the separate measurement of public sector productivity. Further complications arise in comparing outcomes to outputs -for instance, public health and environmental factors as well as hospital or General Practitioner (GP) treatments affect health outcomes. Here, we focus first on outputs, but outcomes are what matter in contributing to the productivity of the whole economy, and we return to this in the final section.

According to the published statistics to date, public services' contribution to GDP plunged in the UK in mid-2020, in contrast to some other European countries: figure 1 shows the quarterly percentage changes in volume terms general government final consumption expenditure (GGFCE) for the UK and four European Union (EU) countries. The public service outputs included in these figures are not quality adjusted. The measurement methods differ in the scope of the use of the 'outputs=inputs' approach compared to direct measurement of activities, and in the construction of index numbers of output across different activities. It is not clear to what extent the contrasts are due to differences in measurement

\footnotetext{
${ }^{1}$ New Zealand, Malaysia and a small number of others are noticeable exceptions who have also moved this agenda forward.
} 
27.0

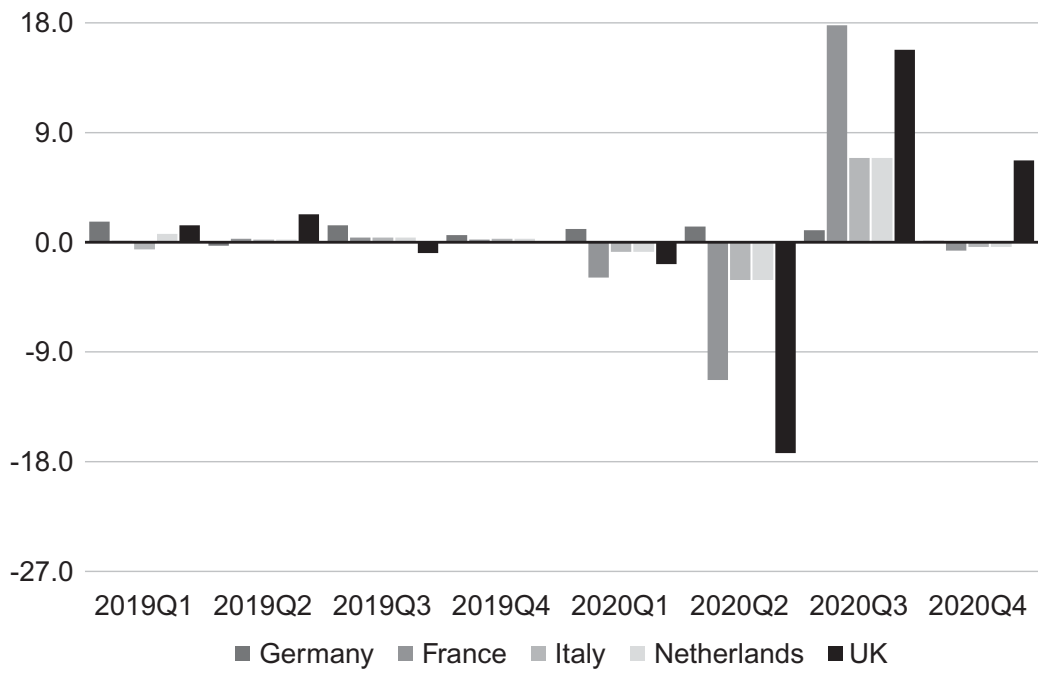

Figure 1. Quarterly percentage change in general government final consumption expenditure (GGFCE), volume terms, SA Source: https://ec.europa.eu/eurostat/databrowser/view/teina031/default/table?lang=en; ONS 22/12/20 Economic Accounts release for UK figures (KH2J); https://www.ons.gov.uk/economy/nationalaccounts/uksectoraccounts/datasets/unitedkingdomeconomicac countsmainaggregates

methods, and an Organisation for Economic Co-operation and Development (OECD)/ONS project is under way to compare measures across different countries. Meanwhile, ONS has reported that their discussions suggest direct measurement is generally used to a lesser extent than in the UK. ${ }^{2}$

The evolution of health service measurement in the UK-both the volume-terms output figures feeding into GDP and the separate productivity figures-is described in Foxton et al. (2019). The 1993 System of National Accounts (SNA) first recommended moving away from the 'outputs=inputs' convention in favour of direct output measures for public services, as discussed below. ONS implemented this in the UK, but other statistical offices either did not, or did so to a lesser degree, or used alternative measures altogether. The UK's early experience of making this switch in the late 1990s was paradoxically to make measured public service productivity decline, the explanation being that statisticians initially used certain activity input measures (such as number of operations) rather than health service output measures (the health improvements resulting from the operations). The Atkinson Review (Atkinson, 2005), commissioned as a result, therefore firmly recommended what it described somewhat loosely as a 'value added' approach, in line with the principles of national accounting. ${ }^{3}$ In other words, what was the difference the public service activity made to health? The Atkinson Review led to refinements in the measurement of direct outputs and also the quality adjustment of outputs. Its perspective was adopted in the 2008 SNA but not in the EU's 2010 ESA guidance. Hence, the UK public service output and GDP have been to date constructed differently from the separate UK public service productivity figures, as explained further below. ONS has gone further than other statistical offices in developing these latter, quality-adjusted, productivity figures, but these are not used in constructing the output figures in GDP.

\footnotetext{
${ }^{2}$ https://www.ons.gov.uk/economy/grossdomesticproductgdp/articles/internationalcomparisonsofgdpduringthecoronavir uscovid19pandemic/2021-02-01

${ }^{3}$ In other words, the direct marginal contribution of activity to output. Phelps (2010) notes though that the public service output measures do not net off intermediate purchases.
} 
However, even within the ESA 2010 framework, countries differ in the extent to which they use the outputs=inputs versus direct output measures (Schreyer and Mas, 2018, table 1.1). As figure 1 shows, the profile of change in volume-terms government expenditures thus differs greatly across countries.

To explain the UK decline, public service output in UK GDP, comprising one-fifth of the total, is currently measured as follows: ${ }^{4}$

A. Just under two-fifths of the total (37.8 per cent in 2015) and 10.1 per cent of healthcare is still measured using the 'outputs=inputs' convention, with inputs consisting of labour, capital consumption such as the depreciation of buildings or equipment, and intermediate purchases such as supplies. This category covers 'collective services' such as defence.

B. The remaining 62.2 per cent of total public service output (and 89.9 per cent of health) is measured as 'quantity output'. The volume of output is a cost-weighted activity index: the sum of the change in the level of different activities, which in the case of hospitals are grouped in terms of the diseases treated, weighted by their unit costs ${ }^{5}$ :

$$
\Delta O_{t}=\sum u_{j, t-1} a_{j, t} / \sum u_{j, t-1} a_{j, t-1}
$$

where $\Delta O_{t}$ is the current period output change, $j$ indexes activities $a$ and associated unit costs $u$. Examples of activities are specific hospital treatments, GP appointments, drugs dispensed and so on. If the mix of activity shifts in the current period shifts such that activities accounting for a smaller proportion of the total the previous year become more frequent, or those which were more common and have a higher weight become less frequent, activity this output index will decrease. Although better than the older convention, this method will be misleading if a cost reduction is due to, say, a new technique that delivers the same or better outcomes at lower cost, as has happened with many medical procedures over the years such as cataract or varicose vein treatments.

The output mix changed significantly during the course of 2020 , while the existing weights were applied in constructing the statistics (table 1). Nominal health expenditure has increased (most of the increase occurring in the second quarter of 2020). But the volume of health output in this Laspeyres-type index consequently declined in the second quarter (recovering partially in the third) due to the composition change: a cessation (and then Q3 recovery) in elective activities despite an increase (substantial in Q2) in Covid-19-related care, mostly critical care. Activities that declined or halted in Q2 such as GP visits, outpatient appointments and elective procedures, along with A\&E visits, ${ }^{6}$ account for about three quarters of current quarterly health service output by weight (Athow, 2020). ${ }^{7}$ Critical care -the main area of increased activity for Covid-19 patients-accounts for just 3.2 per cent of weighted health output on the basis of existing weights. In addition, new health service activities have been introduced-test and trace in 2020, and vaccinations in 2021-which need to be added to the output

\footnotetext{
${ }^{4}$ In calculating the separate public service productivity figures, just under one-fifth (17.7 per cent of the total in 2015, 9.8 per cent of healthcare) is derived using the cost-weighted activity index in B. The remaining just over two-fifths (44.5 per cent in $2015,80.1$ per cent of healthcare) quality adjusts the 'quantity output' measures to address this issue. Specific, complex and model-based, quality metrics are used to adjust the volume of output initially constructed by the quantity output approach (B) (Castelli et al., 2018; Hardie et al., 2010; Peñaloza et al., 2010). In principle, the quality adjustments take the implied deflator closer to the valuations users place on the different activities rather than using the costs to producers (Diewert, 2018; Diewert and Fox, 2017). These quality-adjusted statistics are used in the ONS's stand-alone public service productivity measures, but they are not currently used in constructing GDP or the whole economy productivity statistics

${ }^{5}$ The UK also uses a more detailed categorisation of activities (Healthcare Resource Group classifications) in its full year health output figures than some other OECD countries (typically using Diagnostic Related Group classifications), so compositional changes may play a bigger role for this reason too.

${ }^{6} \mathrm{~A} \& \mathrm{E}$ visits also declined sharply, including paediatric visits (Hughes et al., 2020)

${ }^{7}$ There are additional services in the annual healthcare output measure for which data are not available quarterly or on a timely enough basis to include in quarterly GDP (including mental health, community and ambulance services), so the listed services account for a smaller portion of final annual healthcare output 'benchmark'.
} 
Table 1. Weights in health output

\begin{tabular}{lc}
\hline High level activity & Weight (per cent) \\
\hline GP visits & 21 \\
\hline Elective inpatient care & 19 \\
\hline Non-elective inpatient care & 18 \\
\hline Outpatients first attendance & 5 \\
\hline Outpatients follow-up attendance & 8 \\
\hline Drugs & 15 \\
\hline A\&E & 6 \\
\hline Critical care & 3 \\
\hline Dental & 5 \\
\hline Optical & 1 \\
\hline NHS Direct & 0.3 \\
\hline NHS Online & 0.01 \\
\hline
\end{tabular}

Source: ONS

index using weights that need to be defined as there are no past data. ONS has been making approximate upward adjustments for the new activity of test and trace, and later for the vaccination programme. ${ }^{8}$ Overall, the changing mix led to a large increase, mainly in Q2, in the implied deflator and a decline in quantity output.

Some other countries, such as Germany, use a Paasche-type index to deflate the change in the nominal value of output:

$$
\Delta O_{t}=\sum u_{j, t} a_{j, t-1} / \sum u_{j, t-1} a_{j, t-1} .
$$

It could be argued that the UK output statistics have a downward bias while those constructed on this alternative basis have an upward bias. Another perspective would be to argue that the UK figures should have incorporated altered weights within-year to reflect the substantial mix change, despite the incompleteness of the available data. Moreover, the capacity constraints in the NHS do imply a worse output performance compared to less constrained health systems due to a larger decline in non-Covid treatments, and it would arguably be misleading to adjust the output decline away through changing the weights used in its calculation. For although the weights on different activities will be updated in future years to reflect (to some degree) the 2020 changes, the decline in non-Covid-19 health service outputs has been substantial and is a genuine phenomenon (figure 2); for instance, elective care procedures in 2020Q3 were at less than one quarter of the level in the final quarter of 2019, whereas the largest category (by pre-existing weight) was GP visits, at 62 per cent of their 2019Q4 level in Q3. The number of completed treatment pathways were less than half the previous year's level in April and May 2020, and still 25 per cent lower in December 2020. ${ }^{9}$ NHS Digital figures indicate that 5.12 million people were waiting for treatment by April 2021, up from 3.94 million in April 2020. ${ }^{10}$

\footnotetext{
${ }^{8}$ https://www.ons.gov.uk/economy/grossdomesticproductgdp/bulletins/gdpfirstquarterlyestimateuk/octobertodecem ber2020\# expenditure The data on the new activities are likely to be revised through 2021 as new data sources and enhanced methods become available.

${ }^{9}$ https://www.england.nhs.uk/statistics/statistical-work-areas/rtt-waiting-times/

${ }^{10}$ https://www.england.nhs.uk/statistics/statistical-work-areas/rtt-waiting-times/rtt-data-2020-21/
} 


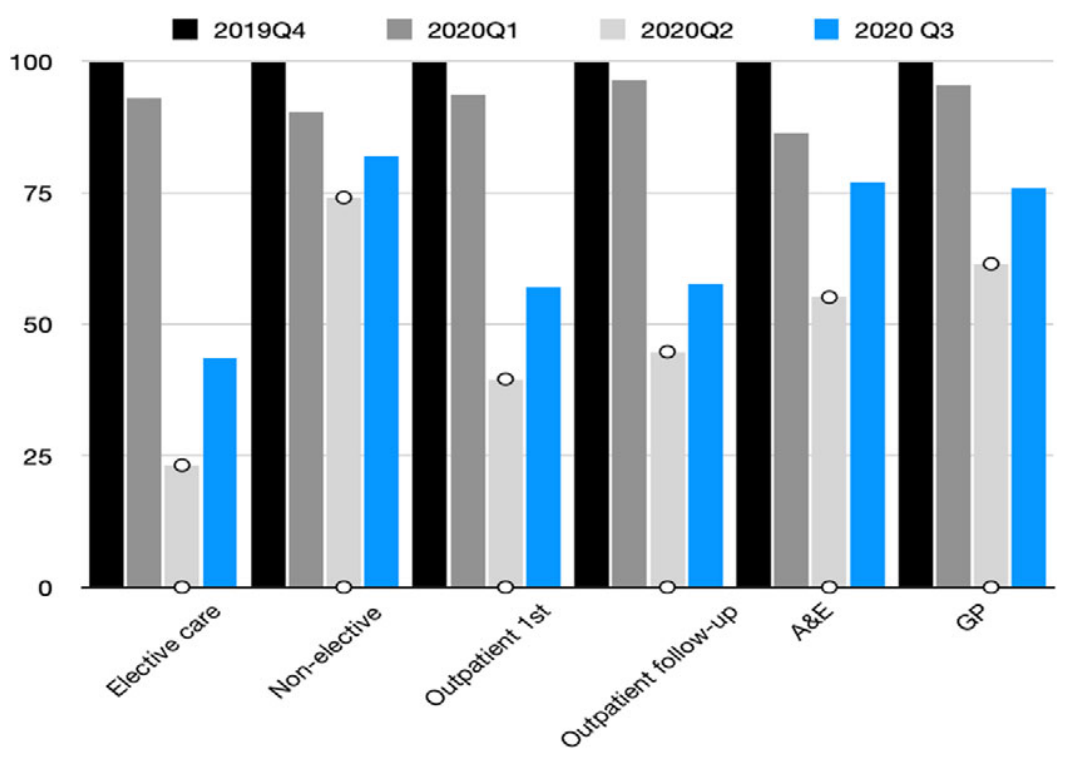

Figure 2. (Colour online) Selected non-Covid-19 NHS activities, 2019Q4-2020Q3

Source: https://www.ons.gov.uk/economy/grossdomesticproductgdp/articles/internationalcomparisonsofgdpduringthecoronavirus covid19pandemic/2021-02-01

Hence, ONS judgements about the weights to apply to 2020 and in future years will be difficult even with hindsight, depending on the extent to which the pandemic experience is considered exceptional. Countries without the same tight capacity constraints have not had to reduce other health activities to the same extent, however (although it is worth noting that prior to the pandemic some of these-such as Germany-were criticised for inefficient hospital over-capacity). ${ }^{11}$ These declines in activity will also have a lasting effect on health outcomes through reduced screening, late diagnosis, delayed treatment and increased incidence of mental ill-health, on top of the adverse consequences of the recession on health through higher unemployment and reduced incomes (Banks et al., 2020; Miles et al., 2020; Thorlby et al., 2020). We return to the question of outcomes, and the organisation and constraints on the NHS, in the final section below.

The discussion so far has referred to health output on the SNA basis. The separate ONS productivity measures will quality adjust outputs (Kent, 2020) as well as accounting for inputs. The volume output measure in (1) above will be divided by volume inputs:

$$
\sum w_{i, t-1} x_{i, t} / \sum w_{i, t-1} x_{i, t-1}
$$

where the $x_{i}$ are activities and $w_{i}$ the associated costs. Some of these inputs-labour, supplies (such as PPE, oxygen and ventilation equipment) and spending on buildings (to fit them for new infection control requirements or augment oxygen delivery systems for example) will have increased substantially in 2020 .

To explore the drivers of productivity in the Covid-19 context, we turn to a qualitative approach, interviewing senior clinicians in two major English NHS hospital trusts. First, we briefly describe the context of successive organisational changes and spending control in the English NHS, as it explains the capacity limits on health service output in the face of the pandemic-related surge in need.

\footnotetext{
${ }^{11}$ For example, https://www.euro.who.int/_data/assets/pdf_file/0008/255932/HiT-Germany.pdf
} 


\section{NHS England context}

While private healthcare exists in the UK, the provider of primary care for the vast majority of the population is the government-funded NHS (Majeed et al., 2020). Total current healthcare expenditure in 2018 was $£ 214.4$ billion, and both total and per capita measures have risen in real and nominal terms every year between 2014 and 2018 . The NHS England budget was $£ 148.8$ billion in $2019 / 20$, increasing to $£ 201.7$ billion in $2020 / 21$, which included $£ 50$ billion for Covid-response. Health expenditure has broadly remained a broadly constant share of GDP at 10.0 per cent since 2011, but this is up from 6.9 per cent in 1997. However, spending increases have not kept pace with demand increases and the NHS was struggling to cope practically and financially before 2020 (PAC, 2020). The government finances 78 per cent of all healthcare expenditure, with the majority of this (64 per cent) spent on curative or rehabilitative care. Only 4.8 per cent of government healthcare expenditure was on preventative care, including early detection of disease, and this has been falling in real terms since 2015, largely due to falls in spending on public health services by local authorities (ONS, 2020).

An important part of the context for understanding health services during the pandemic and prospects for future output and productivity is therefore the already-high pressure on the service. In addition, there has been frequent, complex organisational change, as we sketch briefly here.

Our interview hospital trusts are within NHS England. In general, health services in the devolved nations have diverged away from NHS England structures, with less emphasis on competition (Watson and Komashie, 2020). Within England, healthcare was formally devolved to Greater Manchester in 2016.

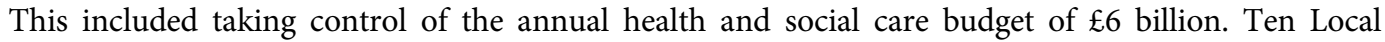
Authorities, 12 Clinical Commissioning Groups (CCGs), and 15 NHS trusts and foundation trusts were involved. However, there was no change in budgets, accountability structures or governance arrangements (Walshe et al., 2018). Manchester is also notable for now having one of the largest acute Trusts in England, running a group of nine hospitals and over 20,000 staff. Three existing hospital providers, Central Manchester NHS Foundation Trust, the University Hospital of South Manchester NHS Foundation Trust and North Manchester General Hospital were merged in October 2017 to form the Manchester University NHS Foundation Trust.

Since the 1980s, the NHS and NHS England have been subject to a series of reforms aimed at increasing efficiency and introducing private sector management practices. This included the creation of an internal market within the NHS, which mandated a distinction between NHS organisations buying services and those providing the healthcare services. Criticism grew over the 1990s concerning the fragmentation of healthcare and also a desire for digitisation, which required collaborative efforts. Subsequent reforms were nominally a reverse of the drive toward managerialism, but maintained the internal markets, centralisation, and targets that were features of the previous reforms (Dalingwater, 2014). The 'multiple, overlapping, and often contradictory reforms' of the NHS in recent decades have been criticised for creating conflicting incentives for both collaboration and competition between NHS organisations (Walshe et al, Walshe et al., 2018). However, Propper (2018) shows that increasing competition within NHS England has had broadly positive results for patients, although its implications for productivity are less clear.

As of 2017, there were 27 agencies and public bodies within the NHS, summarised in figure 3 . The largest of these is NHS England, with responsibility for planning and buying health services in England since the latest set of reforms in 2012. It also plans a large part of NHS strategy (Powell, 2018). In turn, most of the budget of NHS England is passed on to over 200 CCGs, also formed in the 2012 reforms, which plan for health services in their local area, and buy the services from various organisations, such as NHS Trusts running hospitals and community services, and GP practices (King's Fund, 2017). Separate to the CCGs, many NHS England bodies have developed sustainability and transformation partnerships as a collaborative effort between NHS commissioners, providers and local authorities. The 2012 legislative reforms were designed to increase competition, and therefore these collaborative efforts can be restricted by competitive tendering rules (Alderwick, 2020), illustrating the tensions between the competitive and collaborative approaches to NHS organisation. 


\section{The organisations that oversee, support and deliver health and social care}

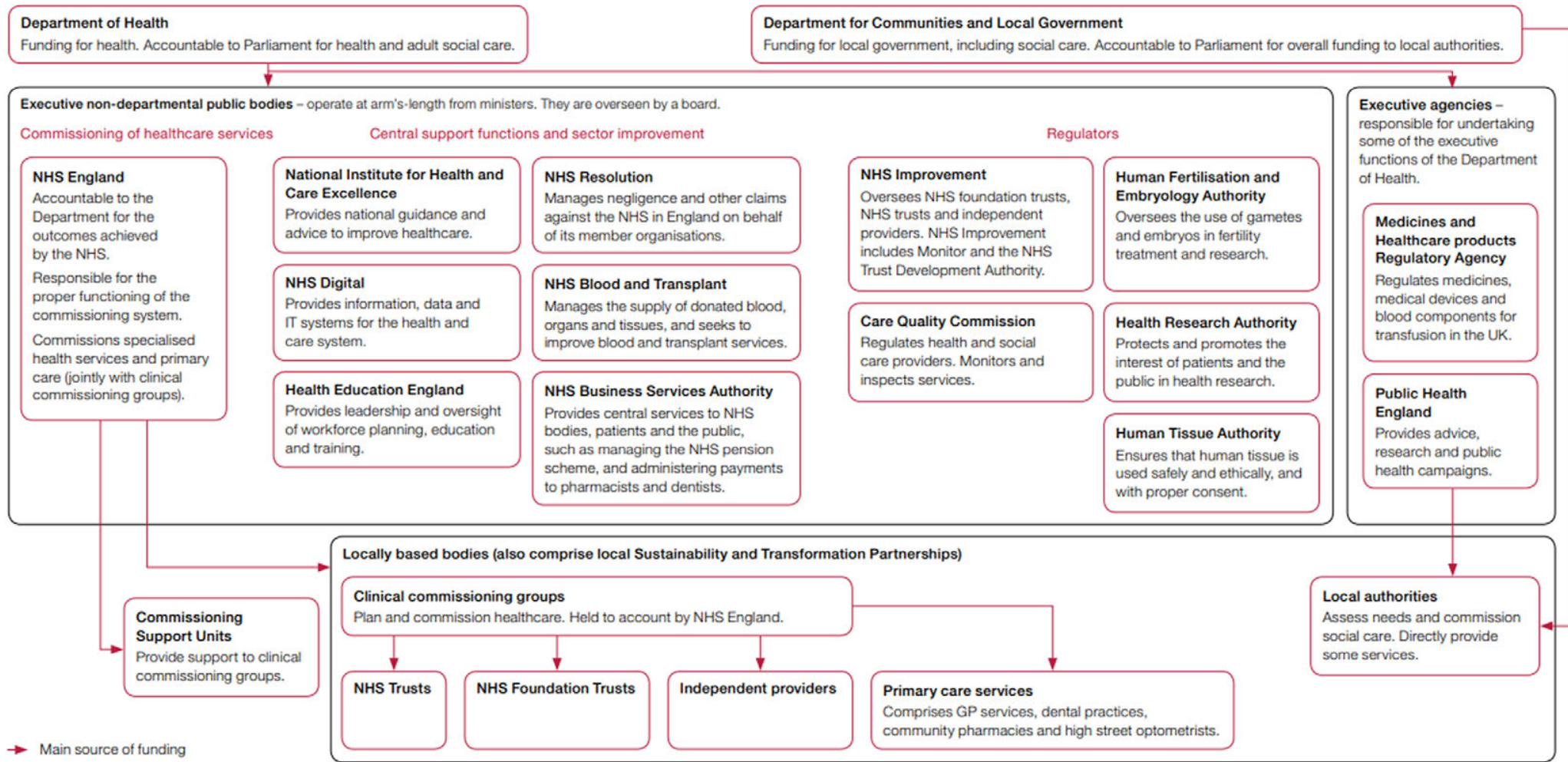

Note

To simplify the diagram, we have not included: NHS Property Services Limited (a company wholly owned by the Secretary of State for Health); advisory non-departmental public bodies such as the NHS Pay Review Body and Review Body on Doctors' and Dentists' Remuneration; and a number of other bodies such as the National Information Board.

Figure 3. (Colour online) Organisation of NHS England

Source: NAO https://www.nao.org.uk/wp-content/uploads/2017/09/2017-Short-Guide-to-the-Department-of-Health-and-NHS-England.pdf 
In January 2019, the NHS published another new long term plan and five year framework. A key part of this plan involved new primary care networks (PCNs), formal structures for large scale GP collaboration. Since May 2020, nearly all GP practices have been incorporated into around 1250 geographical networks, typically covering 30-50,000 patients, and normally contained within one CCG (Baird and Beech, 2020). At the outset, all GP practices were expected to join a PCN and could only access certain new funding streams by doing so. This funding is intended to compensate individual practices for their collaborative efforts, and also to deliver an expanded variety of primary care services, specified by the NHS, that will be mandatory for PCNs to provide in future. The networks are intended to focus on the wider health of the local population and include more preventive care. However, there are concerns over the current feasibility of delivering these services in all PCNs. In addition, the geographic areas for PCNs were not based upon existing collaboration networks, which may be disrupted (NHS Confederation, 2020).

As we write this, another White Paper proposing health service reform has been published, creating a duty for the NHS and local authorities to co-operate to integrate care, and reducing bureaucracy including by amending competition law to enable joint provision of services (Health Policy Insight, 2021). The proposed changes mark a significant move away from the prior emphasis on competition within the NHS, ending the 'internal market', and also indicate a shift toward centralisation of decisionmaking. ${ }^{12}$

Two contextual issues have particular relevance for the productivity outlook.

\subsection{NHS digital/NHS X}

Digitisation has been seen as a potential source of increased efficiency and productivity in the NHS, yet the record of introducing digital technology has been mixed. There are two separate agencies dedicated to incorporating digital technology into health and social care. They are NHS Digital, founded in 2016, focussed on delivery support, and NHSX, founded in 2019, which focuses on strategic change. Both have been involved in aiding the Covid-19 pandemic response in terms of technologies such as remote monitoring, video conferencing, and 111 coronavirus services; easing the regulatory burden of data compliance governance and delivering the NHS Covid-19 app (Lovell, 2020).

\subsection{Staff shortages}

A key concern prior to the pandemic was the significant shortage of NHS staff. Based on pre-pandemic data up to February 2020, there was a projected shortfall of over 115,000 full time equivalent staff in England, projected to double over the next 5 years and more than treble in the next 10 years (Shembavnekar, 2020). In particular, there were prior shortages of nurses and GP staff. In the FYE 2018, a year with a 2.3 per cent increase in overall labour inputs to the NHS, FTE nursing staff numbers fell by 0.2 per cent and GPs and GP staff numbers fell by 0.9 per cent (ONS, 2020). The UK also has one of the lowest rates of doctors relative to its population in the OECD, with 2.8 doctors per 1000 people compared to the OECD average of 3.5 (OECD, 2019). In the first UK lockdown, several measures were taken to address hospital shortages, such as the early graduation of final year medical students, and an agreement with funding bodies to allow those working in education, research or inspection to return to clinical duties. There was also some redeployment of staff within to departments with greatest need with rapid training to facilitate this (Alderwick, 2020); but the relevance to future constraints on health output is the limits on redeployment given the specialised skills and experience required for so many roles.

The pandemic therefore arrived in a context of a health service that has seen successive re-organisations, a strong emphasis until recently on competition and efficiency targets, and also clear evidence of prior pressures on the service-mainly manifesting as staff and bed shortages. There will be

${ }^{12}$ https://www.gov.uk/government/publications/working-together-to-improve-health-and-social-care-for-all 
lasting changes in NHS processes affecting output and productivity. To gain more insight into the impact of the pandemic, we conducted some interviews with senior clinical leaders in two large NHS England hospital trusts.

\section{Changes in hospital practice during the pandemic}

Hospitals are at the frontline of public health response to pandemics. The speed at which Covid-19 can propagate through a population, and the criticality of the symptoms, lead to peaks in demand for hospitals which are usually not designed to provide the required capacity. In consequence, medical and non-medical executives have to make critical decisions regarding clinical operations and resource allocation, with implications for their day-to-day productivity. To get additional insight into what has happened in hospitals specifically during 2020, which changes might persist, and their potential future productivity impacts, we conducted semi-structured interviews in two hospital trusts, Addenbrooke's in Cambridge, and the Manchester Foundation Trust, in November and early December 2020 (see Appendix for methodology).

Based on the interviews, here we describe key elements, challenges and enablers of the response strategies taken to create surge capacity for the delivery of services during the pandemic. Although the number of interviews was small, there were consistent themes (see Appendix).

\section{1. 'Incredibly busy and incredibly idle': the dynamics of Covid-19 and non-Covid-19 care}

In spite of earlier epidemics such as Severe Acute Respiratory Syndrome (SARS), Middle East Respiratory Syndrome (MERS) and H1N1 influenza, hospitals were caught unprepared by the Covid-19 pandemic. The expectation of an imminent large influx of patients suffering from an insufficiently researched, highly transmissible disease at unknown scale was fuelled by the images from other European countries of patients suffocating in hospital corridors. This perception induced significant efforts towards service reconfiguration at all levels of the UK healthcare system. National authorities, medical societies and academic scholars set out to issue guidelines advising on the management of Covid-19 patients and reconfiguration of hospitals to minimise the risk of nosocomial transmissions. ${ }^{13}$ Like others, the hospitals in Manchester and Cambridge quickly reacted to the anticipated increase in demand by undertaking multiple modelling and planning activities to identify resource gaps and create surge capacity:

'So we were constantly trying to say there's this tidal wave-that we don't know the size of it (...) coming towards us of a particular group of patients and we need to prepare for that. And those patients are infectious. And you need PPE. And a lot of them need ventilators, we haven't got enough ventilators; a lot them need critical care, we haven't got critical care staff.

A key element of the early response strategy was the launch of an extensive human resource activation and upskilling programme. While recently retired medical staff and staff in education or research made themselves voluntarily available for clinical duty, hundreds of staff entered a retraining programme to provide adequate capacity in critical care. These activities were complemented not only by the large-scale cessation of non-essential services including elective, outpatient and diagnostic activities, but also by the discharge of medically fit hospital inpatients. This was supported by an increased effort to obtain social care.

As a consequence of these early changes, staff and bed resources freed up, rendering several departments of the hospital idle. This effect was further enhanced by the shift in behavioural patterns that could be observed in the community even before lockdown measures taken by the government

\footnotetext{
${ }^{13}$ Nosocomial transmissions are those resulting from a visit to or stay in hospital.
} 
ED Attendances

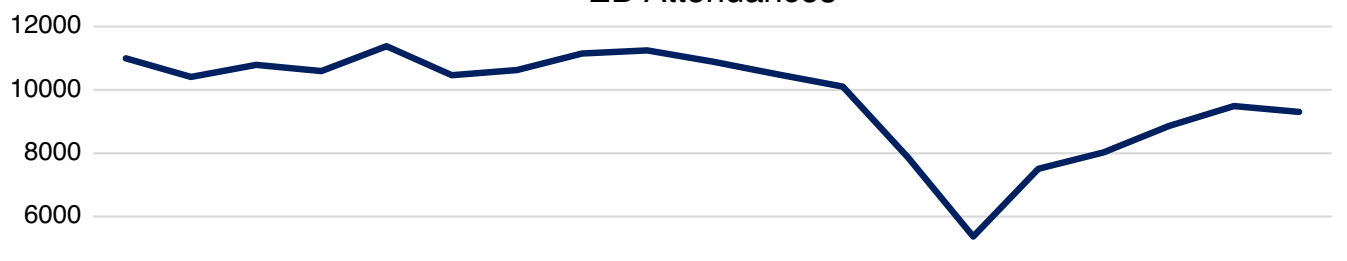

4000

2000

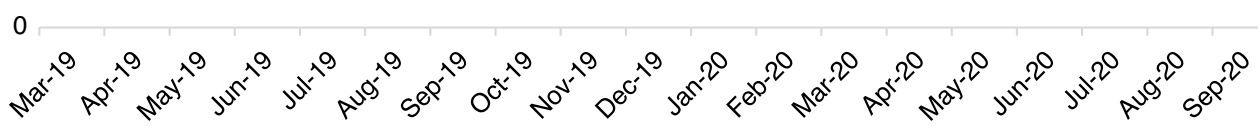

Figure 4. (Colour online) Emergency attendances at Addenbrooke's hospital (March 2019 to September 2020)

Source: https://www.england.nhs.uk/statistics/statistical-work-areas/ae-waiting-times-and-activity/ae-attendances-and-emergencyadmissions-2020-21/

became effective. The 'Stay at Home' campaign led to a steep decline in demand for emergency services. For instance, at Addenbrooke's hospital, the number of patients turning up at the Emergency Department dropped by about 50 per cent (figure 4). These circumstances allowed the hospitals to focus on the treatment of Covid-19 patients and critically ill inpatients, accelerating their learning about the new disease and enabling a higher-than-usual turnaround of patients. Productivity was broadly perceived as high during these early phases of the pandemic:

'The big thing that made a big difference to how we can look after our patients, was a combination of reduced demand and an increased supply of beds. And that meant that we were able to look after our patients much better. Patients who needed admitting, could be sent admitted quite quickly. Patients who could be discharged home could be seen earlier and sent home earlier. So, the thing that made a big difference was, you know... It helps having more staff on a bed. But the big thing that made a difference was actually reduced crowding'.

Despite the advantages of focussed learning and the capacity to undergo organisational change, it was nevertheless quickly recognised that the delay and cancellation of diagnosis and treatment for non-Covid-19 patients could potentially lead to harmful exacerbation of the conditions of these patients. As such, the public was encouraged later in the spring and summer of 2020 to make use of emergency services again and non-Covid-19 services were gradually restarted although not reaching pre-Covid-19 baseline levels before cancellations began again with the beginning of the new year. Simultaneously running Covid-19 care and several services of non-Covid-19 care had significant implications for the availability of the resources and operationalisation of infection control.

\subsection{Infection control in focus: resource availability impairing productivity}

Many of the guidelines that were issued nationally and locally required a reorganisation of clinical pathways and processes affecting operational performance metrics and capacity availability. There are several elements explaining the productivity issues in hospitals during the ongoing Covid-19 pandemic flagged up in the interviews.

Loss of absolute capacity. Infection-control guidelines demanded social distancing be practiced in all areas of the hospital. For example, greater distances between beds were required on the wards, to ensure appropriate patient segregation. In addition, some areas were designated for 'donning and doffing' of 
PPE. This led to a significant reduction in available space and thus absolute bed capacity. In these extensive reconfiguration efforts, the estate was broadly perceived as a primary limiting factor with hospital building layouts not designed for such practices:

'(...) we had a ridiculous time during the escalation of the first wave, when there were only three or four patients in what would normally contain 14 ICU patients. And that's a big impact (...) What we did was we built a wall. We walled off that seven bays so that it could be considered as being geographically distinct from the six bedded bay'.

Loss of functional capacity. To ensure patient segregation, hospitals designated wards for different types of patients (i.e. Covid-19 positive, Covid-19 negative and Covid-19 susceptible) limiting their flexibility in bed allocation. An outbreak in an intentionally Covid-19-free ward could thus cause a sudden drop in available bed capacity. Patients would be required to get tested and potentially moved to other areas in the hospital while an additional cleaning demand during times of already extraordinary cleaning requirements would be created, rendering wards not usable for an unforeseeable period of time.

Limited planning capability. While guidelines were regularly updated, and sometimes conflicting, little room was provided for staff to synthesise, interpret and translate information into actionable operational processes that were both feasible and comprehensive for staff and patients. The informational instability created more-than-necessary caution among operational staff impairing planning capabilities, especially for patients in surgical services:

'Should we isolate a patient for 14 days? And then it was 3 days, but some surgeons might want to keep 14 days if they're having the big cancer cases. And then, patients are then confused what did that mean for their families, so did the whole household have to isolate? (...) And at the beginning, PPE changed so constantly, very difficult to operationalize'.

Non-availability of staff. Over time, hospitals went from 'being massively overstaffed to being massively understaffed'. Populating non-Covid-19 services with staff after significant redeployment required another reorganisation of team structures and adjustment of rotas. This proved a difficult endeavour in multiple ways. Based on a risk assessment of their morbidity, certain members of staff were limited to work in specific areas of the hospitals only. With a higher prevalence of Covid-19 within and outside the hospital with the onset of a second wave, a higher percentage of the overall workforce became infected or needed to self-isolate. In addition, an undoubtedly substantial effect on staff availability was the continuous exposure to pressure, change and ambiguous timelines, with adverse mental and physical consequences among frontline staff. The additional staff being sent to critical care were often not trained for the assigned roles and, while often helpful for some tasks, this created more pressure on the ICU nurses who had to repeatedly train up incoming ward nurses. The following interview excerpt gives insight into the situation of staff deployed to critical care:

'For example, one of their theatres, the day surgery theatres (...) sent us [critical care] staff. (...) They've struggled with the exposure to patients that they would never be exposed to normally (...) You don't anticipate that you're going to have to provide last rites to a patient and (...) send them to the mortuary'.

Shift in case mix. The pressures on the bed base were further aggravated by the shift in case mix observed in elective surgery patients. The introduction of prioritisation schemes to manage congested waiting lists of surgical specialties was intended to enable surgery for those patients with the highest clinical priority first. Yet this shift in case mix towards a higher proportion of patients undergoing highly invasive and complex surgery was associated with longer average lengths of stay for these patients. In addition, for some already critically ill patients, the waiting time had already caused progression in their disease, increasing the likelihood for higher bed level requirements. In light of the targets being set by the NHS 
that required all hospitals to return between 80 and 100 per cent of baseline surgical activity by the end of 2020 , critical voices have been raised about the appropriateness of those targets:

'To me, this just seems completely out of kilter with what we should be doing. So, should we be only delivering the surgery on patients with the highest clinical priority, or should we be doing high volume numbers? And I think that's very difficult for this organisation to make that decision'.

Longer turnaround times. The implementation of donning and doffing protocols and cleaning requirements created an 'extra layer of processes' which slowed all operational processes down. The impact proved especially strong in surgical areas where surgery and turnaround times were substantially prolonged. To limit exposure to aerosols, workflows inside and outside surgical suites needed to be redesigned. Taking on and taking off extensive amounts of PPE not only extended pre- and post-surgical phases but even required the exchange of surgical teams for procedures exceeding several hours. Another contributing factor was the required time for air-cleaning activities in between surgical cases, especially after aerosol-generating procedures. In consequence, compared to pre-Covid-19 rates, fewer patients could receive surgical treatment

'Even if we've been able to see as many patients through the front door we would never have got through as many patients in a day, given all the PPE and the turnaround'.

Decline in Covid-19 mortality rates. With increasing numbers of treated and recovered Covid-19 patients and further science-based treatment recommendations, learning processes became apparent highlighting the importance of quality-adjusted measures of healthcare productivity:

'We know when to give them steroids, we're better equipped to know when to ventilate them or when to send them for non-invasive ventilation, when to give drugs, when to send them home (...) At the moment, they seem less likely to die. But as a consequence, they might stay in hospital for a bit longer'.

The fluctuations in resource availability together with the resumption of non-Covid-19 care have implications for the efficiency at which hospitals of the NHS are normally run. Implications for future resilience will be discussed in more detail in a subsequent section.

\subsection{Enablers of rapid organisational change and implications for the future}

Our interviews reveal that the rapid organisational change hospitals underwent in the early stages of the pandemic were enabled by (1) a major buy-in of internal and external NHS workforce, (2) the provision of extra funding, (3) the easing of governance processes (4) the creation of surge capacity and (5) setting up enhanced communication and technology infrastructure. Despite the overwhelming tragedy, many interviewees reported that the dynamics during the pandemic helped to overcome red tape, potentially providing an impetus for rethinking the service and future improvement within NHS hospitals:

- Staff recruitment, retention and willingness to change. The willingness of NHS workforce to jointly combat the virus created a common purpose ('Keeping staff and patients safe') and enabled swift changes in hospitals. However, the dynamics of the past months have more recently created stress, fatigue and resistance to further change and the willingness to deliver extra services. At the same time, staff sickness rates have gone up, adding further to a general shortage of nursing staff. A long-term recruitment and retention strategy is required that alleviates the impact on workforce mental health, but maintains an appetite for change in terms of continuous improvement.

- Government funding. The removal of financial barriers by the government enabled hospitals to set up quickly extensive procurement programmes for consumables (e.g. PPE), testing capacity and 
equipment (e.g. ventilators); and also to launch continuous improvement projects previously without funding in place. Money for the use of private facilities allowed hospitals to ease the burden of the waiting lists by delivering surgery offsite. Future funding levels will be critical in addressing the backlog of patients.

- Easing of governance processes. The removal of bureaucratic layers and the set-up of new command and taskforce structures softened the vertical and horizontal boundaries of services and hierarchies in hospitals, and enabled more interdisciplinary coordination. Processes accelerated within hospitals and also in their relationship with the external environment. For example, the discharge of patients to nursing homes in the early stages of the pandemic happened faster than usual as barriers of paperwork and agreements evaporated-albeit with terrible consequences. Yet an acceleration of processes can put quality at jeopardy, as this example shows. Another example is that the urgent need for equipment such as ventilators has cut bidding processes resulting in the procurement of potentially lower quality products. The pace at which hospitals will operate in the future will largely depend on their ability of finding a balance between robust business-as-usual and flexible institutional structures. We found some concern that this pace and flexibility would revert: 'initially (...) there was a huge amount of change, and it was very dynamic, and we've now got a whole load of treacle'.

- Provision of surge capacity. In the expectation of a significant backlog of diagnostics and treatment demand, many hospitals have started to build surge capacity by purchasing more equipment and setting up external modules to enlarge their bed base. Due to the interdependency of hospital services, this has implications for other types of resources. For example, more beds provided for orthopaedic surgical patients creates significantly more demand for radiology services requiring additional capacity for example for computed tomography and magnetic resonance tomography scanning. To avoid bottlenecks within the hospital, a holistic view of the surge strategy is needed, potentially crossing the boundaries of the hospital. For example, prior to the pandemic, the Manchester Royal Infirmary had already bundled head and neck surgical services from other hospitals in the region. This model could hold lessons for endeavours in other regions.

- Technology infrastructure. Hospitals, like many businesses, expanded their technological infrastructure to enable effective remote working. Videoconferencing massively improved communication and coordination within and across hospitals. Likewise, the use of telemedicine for outpatient clinics has bridged an important gap in service availability and helped many physicians overcome their doubts. While there is general consensus among our interviewees that virtual meetings and consultations will have a long-lasting impact on certain hospital services, the necessity of face-to-face encounters in the patient-doctor-nexus is crucial for quality of care. Many interviewees also emphasised the importance of their electronic medical record system. To what extent IT systems will have a long-term impact enhancing co-ordination across different levels of the healthcare system will also depend on their interoperability.

\subsection{Prospects}

The effects of the pandemic remain profound. The second wave (and potentially further ones) further emphasises the need for operational and logistical capabilities to respond to different scenarios in the short-, medium- and long-term for efficient healthcare delivery while maintaining a maximum level of staff and patient safety. Leveraging in-house collected data and knowledge will be crucial for hospitals to drive efficiency projects during the pandemic and beyond. Our interviewees repeatedly highlighted the role of leadership and transparent communication during the pandemic. Hospital executives, nursing managers and department supervisors, thus, need to seek approaches so they are responsive to the concerns of their workforce while navigating the ongoing pandemic. 
Our interviews suggest that some of the changes in NHS services, processes and organisation implemented during 2020 may persist, with implications for future productivity:

- Non-Covid-19 treatments will stay at reduced levels as long as the pandemic persists, with adverse consequences for output given NHS capacity constraints, and hence outcomes overall.

- On the other hand, new activities including track and trace, and vaccination programmes, will add to output. When it comes to measurement, ONS will need to determine the most appropriate weights for different activities and this will involve judgements, including about the extent to which 2020 should be regarded as an outlier year. The experience of the behaviour of the quantity output measure during an extreme year, and the ongoing comparison of methods across countries, may suggest worthwhile changes to methodology.

- There will be lasting changes in the use of physical space in hospitals and in staff practices (such as 'donning and doffing' of PPE) to embed infectious disease control requirements. This will reduce their effective capacity (in-patient and out-patient) in current facilities. Output and productivity levels will thus be lower than in a counter-factual non-Covid-19 world, given current space and staff availability, even with many staff being reallocated to different activities within hospitals.

- The crisis has brought about rapid changes in the use of technology, both workplace productivity technology such as video-conferencing for staff, and technology for use with patients, such as video or telephone consultations. This is discussed further below. The move already under way toward using electronic patient record systems such as Epic will likely be accelerated. Technology adoption by the NHS has a troubled history, however, and there will undoubtedly be challenges (Price et al., 2019).

- There have also been changes in the organisation of services and in governance structures, giving the NHS greater operational flexibility and agility, but it is unclear whether these will last, or whether there will be a reversion to previous structures. Some interviewees feared a return to slower decision-making processes once the sense of crisis has passed.

\section{Health service productivity outlook}

Spending on healthcare as a share of national output has trended upward and is likely to continue to do so, because of ageing and cost pressures (Stoye and Zaranko, 2019). Future governments will naturally seek cost efficiencies and productivity improvements. The ONS figures for health productivity show that since 2010, both input and output growth have slowed, but a greater fall in inputs led to eight successive years of positive (non-quality adjusted) healthcare productivity growth. Taking into account also quality-adjustment, incorporated into the health productivity figures from 2003, on average adds 0.5 percentage points to annual productivity growth. In FY2018, quality adjustment added 0.4 percentage points, with a resulting 0.7 per cent quality adjusted healthcare productivity growth. This was the slowest increase since FY2010 (ONS, 2020).

There will be lasting changes in NHS processes affecting output and productivity, working in both positive and negative directions. Depressing future productivity levels will be the need for permanent Covid-safe (more generally, infection-safe) arrangements and ways of working in the long term, given scientific concern about the likelihood of future pandemic threats (IPBES 2020). This implies, for example, permanently lower bed occupancy in given ward space, fewer appointments for given staff numbers and space constraints, and dual (Covid and non-Covid) spaces in hospital buildings. Potentially boosting productivity on the other hand will be the changed ways of working, including using new technology, introduced almost overnight thanks to the crisis, and in some cases also changed organisational structures and increased flexibility. In primary care, for example, the NHS has moved to a 'total triage' model of care enabled by online, video and telephone consultations (Bakhai, 2020), along with 
tech-enabled remote monitoring (also known as 'virtual wards') to support people with Covid-19 oximetry (Inada-Kim and Donnelly, 2020).

As noted earlier, the measurement of public service health productivity is challenging. The known difficulties in distinguishing activities from outputs, and in quality adjusting as medical innovations continue, reflect inherent conceptual challenges. Atkinson (2005) pointed out that there is no reason to expect productivity improvements in certain services requiring essential human contact-where machines are limited substitutes even in the case of digital technology-or in areas where there has already been so much improvement that it is unreasonable to expect more and the challenge is rather to not regress (such as reduced neonatal mortality). Technology in areas such as robotics has advanced considerably since he wrote this, but there will nevertheless continue to be many services needing human input.

A full conception of productivity should also include a number of outcome improvements that either manifest over time or reflect the management of uncertainty: the insurance value of better infectiousdisease control in a world at risk of experiencing repeated pandemics; the option value of a capacity margin in the event of other types of unexpected peak load demand; and the demand-reduction effects of better preventive care (such as the link between respiratory health and better Covid-19 outcomes).

A broader issue still is the difference between measurement of output and consequently productivity as opposed to measurement of health outcomes and economic welfare. Figure 5 portrays the relationships. It speaks to the fundamental dilemma of being able to measure activities and outputs relatively easily while actually wanting to understand their impacts on economic welfare (Coyle, 2014). Although the UK's health output performance will have been worse than in some other countries because limited capacity reduced non-Covid health activities so considerably, the economic welfare outcome is nevertheless better than it would have been without the adjustments in response to the pandemic.

Drawing on the implications of the 2020 data and our interviews, we conclude with some lessons from the pandemic experience for future NHS productivity as conventionally understood. We argue for a broader conception of the ability of the NHS to contribute to improving health outcomes and thus economic productivity over the longer term.

\subsection{Organisation of healthcare services in the UK}

The history of NHS reorganisation, with swings in philosophy of provision, was described briefly in Section 3, noting that further reform is planned for 2021. A full exploration of the question of the

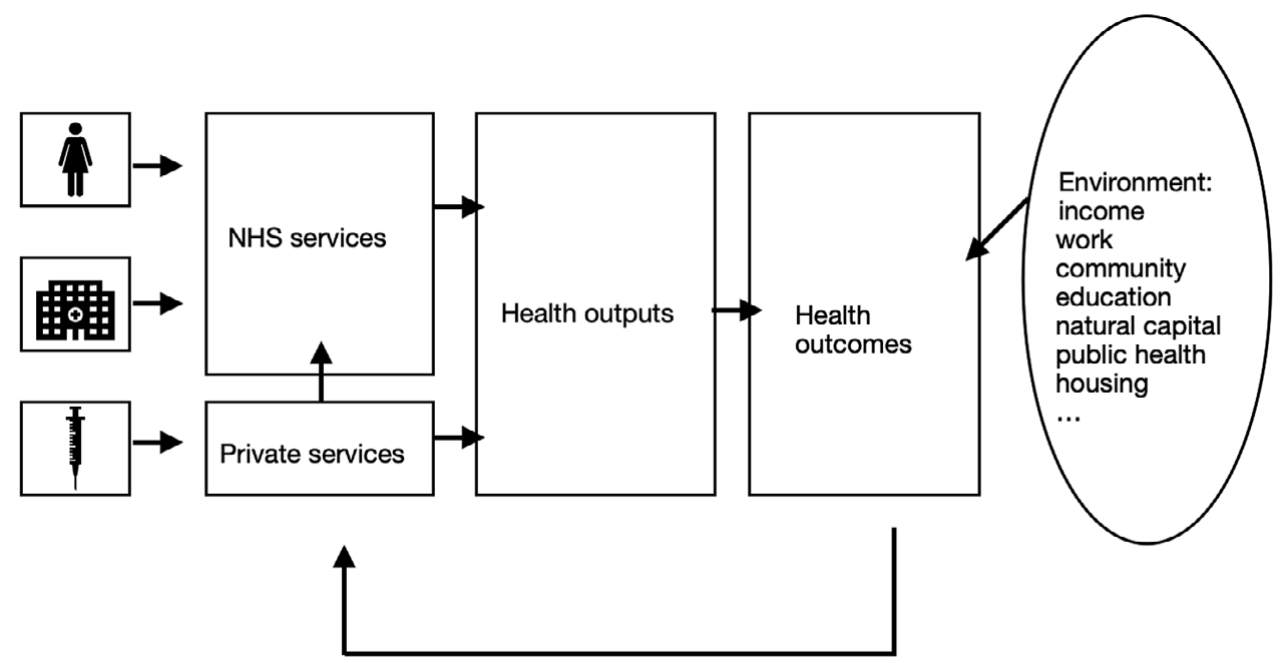

Outcomes determine demand

Figure 5. Health inputs, outputs and outcomes 
institutional structure of the NHS - the balance between central direction and local autonomy, the best geographic scale for organisation, the extent of vertical integration between primary and secondary care, or with public health and social care in the community-is beyond our scope here. It is worth though highlighting some key issues with implications for productivity.

One is the balance between central and local decision-making. Phillips and Propper (2020) argue that NHS England over-localised procurement and over-centralised track and trace, and suggest using the need for flexibility and granular information flow to decide what to decentralise. Issues of internal governance and the difficulty of bringing about productivity-enhancing organisational change within hospitals also emerged from our interviews as important potential barriers; the imperatives of the crisis led to the suspension of normal hierarchies in order to enable change. The pandemic experience will offer an extreme natural experiment permitting an assessment of how these classic organisational dilemmas have played out in different health service activities.

Another important organisational question concerns vertical integration. Among other staff shortages, the shortage of GPs, or family doctors, is particularly striking, and means that in some cases hospitals have taken over GP practices. This vertical integration can help small GP practices stay open and so maintain local access to primary healthcare. These integrated practices have experienced easier recruitment by offering salaried positions without a small practice having to bear financial risk, and also offer more training and achieve (in principle) administrative synergies. It is likely that GP workforce constraints combined with higher patient demand with make primary care in its current form increasingly unsustainable. However, when multiple GP practices are vertically integrated with a single hospital, this effectively creates horizontal integration and limits patient choice of provider, again illustrating collaborative-competitive tensions (Sidhu et al., 2020).

There is also the issue of contracting out. The NHS effectively took over much of the UK's private health system at the start of the pandemic (David Hare, Independent Healthcare Providers Network, quoted in Neville, 2020). While this will unwind, there are open questions about the appropriate extent of future NHS contracting to the private sector, including the use of digital services. As noted above, there has been some increase over time in the scope of contracting out to the private sector. This is politically contentious and its efficacy is challenged. This has been a particular concern during the pandemic, which necessitated a sudden large increase in some procurement activities. For example, the National Audit Office was critical of the contracting involved in the new NHS Test \& Trace service, spending $£ 4$ billion to the end of November 2020, many of which were let to private sector contractors (NAO, 2020). Activities that are straightforward to contract and monitor can be outsourced without an expected loss of quality (Hart et al., 1997; Holmstrom and Milgrom, 1991), but this economic perspective is not the one successive governments have applied to the NHS. NHS reorganisation in the 1990s through to 2012 reflected a broad philosophy of mimicking market-like competition. Vertical integration between hospitals and primary care facilities due to the challenges to the viability of the latter have begun to chip away at the commissioner-provider spilt. There are some major questions for future research concerning outsourcing, especially with regard to technology use, as software supply contracts are notoriously challenging given the asymmetries of information and hard-to-codify character of requirements (e.g. Keil, 2005). Procurement by the NHS must also mandate public service access to all the data collected by the private sector, both for monitoring of service quality and for the flow of information required for productivity of the public service (Coyle et al., 2019).

\subsection{Use of digital technology}

Many organisations are grappling with the implications of digital technology use in production, and NHS bodies are no exception. NHSX was created expressly to assess its adoption in the NHS. Their use will have increased significantly in 2020, from a low base. The pandemic has led to swift uptake of technology both for internal organisation and communication purposes and for patient services. Most of 
our interviewees welcomed the greater use of video consultations, seeing them as more convenient for staff and patients alike, and anticipated that these new practices would persist.

However, there has been relatively little evaluation of the impact of digital patient consultations on health outcomes. To the extent that there has, the organisational structures and regulatory frameworks seem more important than the use of technology per se (Bronsoler et al., 2020; Freed et al., 2018; Shigekawa et al., 2018). There is a large economic literature demonstrating that the productivity benefits of new technologies require substantial investments in organisational change, as the benefits of the technology lie in empowering people to use information do things differently (e.g. Brynjolfsson et al., 2020; Brynjolfsson and Hitt, 2000). While the benefits of some technologies, such as electronic health records, or the enforcement of greater inter-operability in software choices, seem straightforward, broad productivity gains will be related to the questions of organisational structure discussed above. These potential improvements include the flow of information around the system as a whole, which is crucial to determining both productivity (through internal co-ordination and process efficiency) and health outcomes (through joining up information about individuals and delivering co-ordinated services). The flow of information and the authority to take decisions - crucial to productivity and outcomes in a knowledge-based sector such as health-cannot be separated from questions of governance and organisation.

Nor is it clear that digital delivery always saves time, if the outcome of a video call is that the patient still needs an in-person appointment for diagnosis and tests. In time, increased use of individual devices such as smart watches or pulse oxymeters may reduce the need for this double dipping. However, given the cost of such devices, reliance on them could exacerbate already severe health inequalities. Digital may help achieve financial efficiencies at least after initial investment, but it will not be a magic wand for health output and productivity (particularly for the non-quality adjusted measures as lower unit cost procedures will reduce output) or indeed improved broader health outcomes. It is evident that there has been too little focus on the need for interoperability as different parts of the health service have adopted digital technologies. Evaluation of outcomes from the year's substantial increase in telemedicine provision will be an important area of research - and crucially, from the patient as well as the provider perspective.

\subsection{Characteristics of the health production function}

Our interviews (as well as contemporaneous media reports) repeatedly pointed to two significant bottlenecks in NHS provision during 2020: staff shortages and bed shortages. After the earliest days of the epidemic there was no shortage of either ventilator equipment or PPE, although oxygen supplies and configuration became problematic again in December to January. It is evident that for many health activities, not just treatment of Covid-19 patients, there is limited substitutability among staff, equipment and beds, and supplies. Staff can be reallocated, and staff-patient ratios reduced-up to a point. A given procedure on a patient requires minimum ratios of each category. There is no reason to believe that every hospital is already on the production efficiency frontier, although the experience of 2020 will have pushed more of them much closer.

In general, Jones (2005) shows that with low substitutability between inputs, productivity advances will depend on technique changes, or in other words new ideas. There are many examples of medical innovations that are precisely such technique changes, such as keyhole surgery, or vaccinations. However, in the short term, the fixed proportions character of the production function means there will be eventual limits to the scope for efficiency gains. A further implication is that-in the context of increasing demand pressures-over the long term health innovations and their diffusion will continue to be important. Adopting new technologies - say the use of robotics for dispensing drugs-will require investment. The use of centralised NHS procurement as a means of both incentivising innovation by creating a market and then purchasing innovations cost-effectively and diffusing them would represent a change of mind-set from the usual focus on cost-efficient procurement of currently-standard inputs. 


\subsection{Capacity, demand peaks and healthcare as social infrastructure}

Propper et al. (2020) observe that the pandemic hit the UK in the context of pre-existing NHS capacity shortages. Even with 'normal' rising demand, the health service hits peak loading problems, and this has been amply experienced in 2020. The NHS emphasises the importance of workforce planning. ${ }^{14}$ However, not only did the NHS enter 2020 with staff shortages, especially of nurses, the workforce planning guidance does not include consideration of demand peaks-not even standard winter peaks. The implicit assumption is that staff can be 'run' more intensively, but the experience of the pandemic vividly illustrates the toll this takes, in terms of the health and wellbeing of individuals and the increased loss of trained staff, as our interviews revealed. There is a large literature on peak load capacity in the context of utilities such as energy generation, where there are large fixed costs of creating new supply units. In general, Williamson (1966) showed that total surplus or economic welfare will be increased by creating supply capacity sufficient to meet effective demand over an entire demand cycle (although in cases such as energy the optimal prices charged will vary between peak and off-peak periods). He notes that the same analysis applies to any public infrastructure, not just energy.

The analysis of NHS 'surge capacity' during 2020 shows that it was ultimately insufficient to meet Covid-19 and prior demand (McCabe et al., 2020). Hospitals naturally try to plan for expected demand, and their ability to model Covid-19 patient numbers improved over the course of 2020. Capacity need can be modelled in terms of possible increases in demand traded off against 'wasted' capacity such as empty beds, and there are more sophisticated models incorporating queuing. However, the NHS has historically not used these models but instead has adopted 'demand management' (NHS England, 2016; i.e. limiting demand) combined with a 'just-in-time' production approach with regard to beds, staffing and supplies (Pandit, 2020). Thus, for example, NHS England has operated with far high bed occupancy rates and fewer beds per 1000 people than comparable developed economies. ${ }^{15}$ The focus on 'lean production' efficiency meant the NHS was unable to meet peak demand, and instead had to cease nonCovid-19 activities. Surge capacity is further limited by the quasi-fixed-proportions character of the production function.

The experience of 2020 calls this focus on minimal spare capacity into question, even though processtype efficiencies have been an important driver of past health productivity growth. Given the long-term investment required for medical training, which makes its workforce planning conceptually similar to other long-term public investments, and the fundamental importance of health for human capital and economy-wide productivity, the health service should instead be regarded as a key component of the UK's infrastructure. The principles of having capacity to meet anticipated demand peaks would then apply. Economics has not usually included consideration of 'social infrastructure', or the physical assets enabling the delivery of critical collective services such as health (Turner, 2020). However, social infrastructure is increasingly seen as a complement to conventional physical infrastructure as an underpinning for productivity and growth (Corrado, 2021).

This infrastructure perspective makes resilience (in this specific sense of capacity to continue operating in the face of extreme demand loading) key to planning capacity. The Government's own formal guidance on infrastructure resilience-albeit in the context of its aid spending overseas-quotes the UN International Strategy for Disaster Reduction (2009): 'Critical facilities are the primary physical structures, technical facilities and systems which are socially, economically or operationally essential to the functioning of a society or community, both in routine circumstances and in the extreme circumstances of an emergency.' ${ }^{16}$ The UK guidance document notes that health services are generally

\footnotetext{
${ }^{14}$ https://improvement.nhs.uk/resources/best-practice-workforce-planning/; https://www.hee.nhs.uk/sites/default/files/doc uments/180522MedPlanningGuidance201819V1.1.pdf

${ }^{15}$ https://data.oecd.org/healtheqt/hospital-beds.htm

${ }^{16}$ https://assets.publishing.service.gov.uk/ media/57d6bc17e5274a34de000040/Introducing_Infrastructure_Resilience_25May16_rev_external.pdf; https://www.unisdr. org/files/7817_UNISDRTerminologyEnglish.pdf
} 
considered to be part of a country's critical infrastructure, but also notes that the UK's National Infrastructure Commission does not include social infrastructure in its planning.

The perspective of considering some NHS non-capital (on current definitions) spending as investment in peak load capacity for resilience would have implications for health productivity measurement, and one can imagine different approaches. For example, part of health output could be considered a 'collective' service, analogous to defence, and therefore measured by the inputs=outputs approach. A contrasting approach would be to regard the real option of a capacity margin as a quality improvement.

\section{Conclusion}

Although the contrast in performance of health output between the UK and some other European countries is partly a question of measurement methods and different service structures, the tighter capacity constraints in the UK did involve a large decline in the provision of non-Covid-19 services. The UK has under-invested in capacity which provides genuine option value, and the health service could be considered as part of the infrastructure investment needed by the UK. The experiences of hospitals during the pandemic hold important insights for health provision, and thus both directly and indirectly (via health outcomes and human capital) for wider UK productivity performance. In addition to capacity investment in staff and facilities, using the opportunity to embed new ways of working particularly with the use of technology will be important for future NHS productivity.

Acknowledgements. The authors are grateful to Office for National Statistics colleagues for their help, and also to Huw Dixon, Carol Propper, Paul Schreyer, Bart Van Ark, Tony Venables and Martin Weale. The authors also thank the anonymous referees.

Funding. This research was funded by the ESRC's Productivity Institute, grant number ES/V002740/1.

\section{References}

Alderwick, H. (2020), 'NHS reorganisation after the pandemic', available online at https://www.bmj.com/content/bmj/371/ bmj.m4468.full.pdf

Athow, J. (2020), 'The virus, the vaccine and GDP: Measuring healthcare through the pandemic', available online at https:// blog.ons.gov.uk/2020/12/21/the-virus-the-vaccine-and-gdp-measuring-healthcare-through-the-pandemic/

Atkinson, A. (2005), 'Atkinson review: Final report. Measurement of government output and productivity for the national accounts', available online at https://www.ons.gov.uk/ons/guide-method/method-quality/specific/public-sector-methodol ogy/articles/atkinson-review-final-report.pdf

Baird, B. and Beech, J. (2020), 'Primary care networks explained'. The King's Fund. November 20, available online at https:// www.kingsfund.org.uk/publications/primary-care-networks-explained, retrieved on 28 Jan. 2021.

Banks, J., Karjalainen, H. and Propper, C. (2020), 'Recessions and health: The long-term health consequences of responses to the coronavirus', IFS Briefing Note, available online at https://www.ifs.org.uk/publications/14799

Bakhai, M. (2020), 'The use of online and video consultations during the Covid19 pandemic - delivering the best care to patients', NHSX blog, 27 May, available online at https://www.nhsx.nhs.uk/blogs/use-online-and-video-consultationsduring-covid-19-pandemic-delivering-best-care-patients/

Bronsoler, A., Doyle, J. and Van Reenen, J. (2020), 'The impact of new technology on the healthcare workforce', MIT Policy Brief, available online at https://workofthefuture.mit.edu/research-post/the-impact-of-new-technology-on-the-healthcareworkforce/, retrieved on 22 Jan. 2021.

Brynjolfsson, E. and Hitt, L.M. (2000), 'Beyond computation: Information technology, organizational transformation and business performance', Journal of Economic Perspectives, 14, 4, pp. 23-48.

Brynjolfsson, Erik, Daniel Rock and Chad Syverson. (2021), 'The Productivity J-Curve: How Intangibles Complement General Purpose Technologies', American Economic Journal: Macroeconomics, 13, 1, pp. 333-372.

Castelli, A., Chalkley, M. and Santana, I.R. (2018), Productivity of the English National Health Service: 2015/16 Update, York: Centre for Health Economics, University of York.

Corrado, C. (2021), 'Intangible capital, chapter in Brookings Institution', forthcoming.

Coyle, D. (2014), GDP: A Brief But Affectionate History, Princeton: Princeton University Press.

Coyle, D., Diepeveen, S., Kay, L. and Tennison, J. (2019), 'The value of data: Policy implications', available online at https:// www.bennettinstitute.cam.ac.uk/media/uploads/files/Value_of_data_Policy_Implications_Report_26_Feb_ok4noWn.pdf

Dalingwater, L. (2014), 'Post-new public management (NPM) and the reconfiguration of health services in England', Observatoire de la Société Britannique, 16, pp. 51-64. 
Diewert, W.E. (2018), 'Productivity measurement in the public sector', in Grifell-Tatjé, E., Knox Lovell, C.A. and Robin, C. (eds), Sickles: The Oxford Handbook of Productivity Analysis, Oxford: OUP.

Diewert, E. and Fox K.J. (2017), Productivity Measurement in the Public Sector: Theory and Practice, Vancouver: Vancouver School of Economics, University of British Columbia, available online at https://pdfs.semanticscholar.org/634a/ 0bbf731c4269d865dcdc22358bd8e4283be3.pdf

Foxton, F., Grice, J., Heys, R. and Lewis, J. (2019), 'The measurement of public goods: Lessons from 10 years of Atkinson in the United Kingdom', Eurona Issue 2/2019, available online at https://ec.europa.eu/eurostat/cros/content/measurement-publicgoods-lessons-10-years-atkinson-united-kingdom-fred-foxton-joe-grice-richard-heys-james-lewis_en

Freed, J., Lowe, C., Flodgren, G., Binks, R., Doughty, K. and Kolsi, J. (2018), 'Telemedicine: Is it really worth it? A perspective from evidence and experience', BMJ Health \& Care Informatics, 25, 1, pp. 14-18. doi: 10.14236/jhi.v25i1.957.

Hardie, M., Peñaloza, M.-C., Wild, R. and Mills, K. (2010), 'Public service output, inputs and productivity: Healthcare Extended analysis', UK CeMGA.

Hart, O., Shleifer, A. and Vishny, R.W. (1997), 'The proper scope of government: Theory and an application to prisons', Quarterly Journal of Economics, 112, 4, pp. 1127-1161.

Health Policy Insight (2021), 'Government's new health white paper', 5 February, available online at www.healthpolicyinsight.com/?q=node/1699, retrieved on 6 Feb. 2021.

Holmstrom, B. and Milgrom, P. (1991), 'Multitask principal-agent analyses: Incentive contracts, asset ownership, and job design', Journal of Law, Economics, and Organization, 7, pp. 24-52. doi:10.1093/jleo/7.special_issue.24.

Hughes, H.E., Hughes, T.C., Morbey, R., Challen, K., Oliver, I., Smith, G.E. and Elliot, A.J. (2020), 'Emergency department use during Covid19 as described by syndromic surveillance’, Emergency Medicine Journal, 37, pp. 600-604.

Inada-Kim, M. and Donnelly, T. (2020), 'Tech supported remote monitoring for Covid19', NHSX blog, 11 November, available online at https://www.nhsx.nhs.uk/blogs/tech-supported-remote-monitoring-covid-19/

IPBES Workshop on Biodiversity \& Pandemics (2020), available online at https://ipbes.net/sites/default/files/2020-10/IPBES \%20Pandemics\%20Workshop\%20Report\%20Executive\%20Summary\%20Final.pdf

Jones, C.I. (2005), 'The shape of production functions and the direction of technical change', The Quarterly Journal of Economics, 120, 2, pp. 517-549. doi:10.1093/qje/120.2.517.

Keil, P. (2005), 'Principal agent theory and its application to analyze outsourcing of software development', ACM SIGSOFT Software Engineering Notes, 30, 4, pp. 1-5. doi:10.1145/1082983.1083094.

Kent, K. (2020), 'How to compare and interpret ONS productivity measures', ONS, available online at https://www.ons.gov.uk/ economy/economicoutputandproductivity/publicservicesproductivity/methodologies/howtocompareandinterpretonspro ductivitymeasures\#output

The King's Fund (2017), 'How does the NHS in England work? An alternative guide', available online at https://www. kingsfund.org.uk/audio-video/how-does-nhs-in-england-work

The King's Fund (2019), 'Is the NHS being privatised?' available online at https://www.kingsfund.org.uk/publications/articles/ big-election-questions-nhs-privatised

Lovell, T. (2020), 'Government denies plans to create new “NHS transformation taskforce”', Healthcare IT News. 25 November, available online at https:/www.healthcareitnews.com/news/emea/government-denies-plans-create-new-nhs-transforma tion-taskforce

McCabe, R., Schmit, N., Christen, P, D’Aeth, J.C., Løchen, A., Rizmie, D., Nayagam, S., Miraldo, M., Aylin, P., Bottle, A., Perez-Guzman, P.N., Ghani, A.C., Ferguson, N.M., White, P.J. and Hauck, K. (2020), 'Adapting hospital capacity to meet changing demands during the Covid19 pandemic', BMC Medicine, 18, p. 329. doi:10.1186/s12916-020-01781-w.

Majeed, A., Maile, E.J. and Bindman, A.B., (2020), 'The primary care response to Covid19 in England's National Health Service', Journal of the Royal Society of Medicine, 113, 6, pp.208-210. doi:10.1177/0141076820931452.

Miles, D., Stedman, M. and Heald, A. (2020), 'Living with Covid19: Balancing costs against benefits in the face of the virus', National Institute Economic Review, 253, pp. R60-R76. doi:10.1017/nie.2020.30.

National Audit Office (2020), 'The government's approach to test and trace in England - interim report', available online at https://www.nao.org.uk/report/the-governments-approach-to-test-and-trace-in-england-interim-report/

Neville, S. (2020), 'Over the rainbow: What next for the NHS?', Financial Times, 19/20 Sept. 2020.

NHS England (2016), 'Demand management good practice guide', available online at https://www.england.nhs.uk/wpcontent/uploads/2016/12/demand-mgnt-good-practice-guid.pdf

NHS Confederation (2020), 'One year on and one pandemic later: What's happened to primary care networks and other forms of primary and community care collaboration?' NHS Confederation. July 13, available online at at nhsconfed.org/ resources/2020/07/one-year-on-and-one-pandemic-later, retrieved on 28 Jan. 2021.

OECD (2019), 'Doctors (overall number)', in Health at a Glance 2019: OECD Indicators, Paris: OECD Publishing. doi:10.1787/ b33ab4c1-en.

ONS (2020), 'UK Health Accounts: 2018', Office for National Statistics, available online at https://www.ons.gov.uk/people populationandcommunity/healthandsocialcare/healthcaresystem/bulletins/ukhealthaccounts/2018 
ONS (2020), 'Public service productivity, healthcare, England: financial year ending 2018', available online at https://www. ons.gov.uk/economy/economicoutputandproductivity/publicservicesproductivity/articles/publicservicesproductivityesti mateshealthcare/financialyearending 2018

Pandit, J.J. (2020), 'Demand-capacity modelling and COVID-19 disease: identifying themes for future NHS planning', Anaesthesia, 75, pp. 1278-1283. https://doi.org/10.1111/anae.15144

Peñaloza, M.-C., Hardie, M., Wild, R. and Mills, K. (2010), 'Public service output, inputs and productivity: Healthcare', UKCeMGA.

Phelps, M.G. (2010), 'Comparing different estimates of productivity produced by the Office for National Statistics', Economic \& Labour Market Review, 4, 5, pp. 25-29.

Phillips, N. and Propper, C. (2020), 'Centralisation vs decentralistion', available online at https://www.imperial.ac.uk/ business-school/ib-knowledge/management/centralisation-vs-decentralisation-the-disastrous-confusion-the-heart, retrieved on 22 Jan. 2021.

Powell, T. (2018), 'The structure of the NHS in England', House of Commons Library, available online at https:// commonslibrary.parliament.uk/research-briefings/cbp-7206/

Price, C., Green, W. and Suhomlinova, O. (2019), 'Twenty-five years of national health IT: Exploring strategy, structure, and systems in the English NHS', Journal of the American Medical Informatics Association, 26, 3, pp. 188-197. doi:10.1093/jamia/ ocy162.

Propper, C. (2018), 'Competition in health care: Lessons from the English experience', Health Economics, Policy and Law, 13, pp. 492-508. doi:10.1017/S1744133117000494.

Propper, C., Stoye, G. and Zaranko, B. (2020), 'The wider impacts of the coronavirus pandemic on the NHS', IFS Briefing Note, April, available online at https://www.ifs.org.uk/publications/14798

PAC Public Accounts Committee (2020), 'NHS capital expenditure and financial management', Eighth report of session 2019/21, available online at https://committees.parliament.uk/publications/1779/documents/17455/default/

Schreyer, P. and Mas, M. (2018), 'Measuring health services in the national accounts: An international perspective', in Aizcorbe, A., Baker, C., Berndt, E.R. and Cutler, D.M. (eds), Measuring and Modeling Health Care Costs, Chicago: University of Chicago Press for NBER, available online at http://www.nber.org/chapters/c13116

Shigekawa, E., Fix, M., Corbett, G., Roby, D.H. and Coffman, J. (2018), 'The current state of telehealth evidence: A rapid review', Health Affairs, 37, 12, pp. 1975-1982.

Shembavnekar, N. (2020), 'Going into Covid19, the health and social care workforce faced concerning shortages', The Health Foundation. 20 May, available online at https://www.health.org.uk/news-and-comment/charts-and-infographics/goinginto-covid-19-the-health-and-social-care-workforce-faced-concerning-shortages

Sidhu, M., Pollard, J. and Sussex, J. (2020), Vertical Integration of GP Practices with Acute Hospitals in England and Wales: Rapid Evaluation, Southampton: NIHR Health Services and Delivery Research Topic Report. doi:10.3310/hsdr-tr-131295

Stoye, G. and Zaranko, B. (2019), UK Health Spending, Institute for Fiscal Studies, London.

Thorlby, R., Tinson, A. and Craindler, J. (2020), 'Covid19: Five dimensions of impact', Health Foundation, available online at .https://www.health.org.uk/news-and-comment/blogs/covid-19-five-dimensions-of-impact, retrieved on 30 Dec. 2020.

Turner, C. (2020), 'Social infrastructure', chapter 7, in The Infrastructured State, Cheltenham: Edward Elgar Publishing, pp. $152-171$.

Walshe, K., Lorne, C., McDonald, R., Coleman, A. and Turner, A. (2018), 'Devolving health and social care: Learning from Greater Manchester', Devolving Health and Social Care: Learning from Greater Manchester, available online at https:// www.alliancembs.manchester.ac.uk/media/ambs/content-assets/documents/news/devolving-health-and-social-carelearning-from-greater-manchester.pdf

Watson, K. and Komashie, M. (2020), Improving Health Systems IHS1 Organisation of Health Systems, Cambridge: University of Cambridge.

Williamson, O. (1966), 'Peak-load pricing and optimal capacity under indivisibility constraints', The American Economic Review, 56, 4, pp. 810-827.

Glaser, B.G. and Strauss, A.L. (1967), The Discovery of Grounded Theory: Strategies for Qualitative Research, 1st edition, Chicago: Aldine.

Rubin, H.J. and Rubin, I.S. (2005), Qualitative Interviewing: The Art of Hearing Data, 2nd edition, Thousand Oaks: SAGE.

Strauss, A.L. and Corbin, J.M. (1998), Basics of Qualitative Research: Techniques and Procedures for Developing Grounded Theory, Thousand Oaks: SAGE.

Yin, R.K. (2003), Case Study Research: Design and Methods, 3rd edition, Thousand Oaks: SAGE. 


\section{Appendix: Interview methodology}

Qualitative interviews with senior clinical employees of NHS trusts Addenbrooke's hospital in Cambridge and Manchester Foundation Trust were designed in a semi-structured format. Eight interviewees were all senior clinical staff involved in the reorganisation and provision of services during the pandemic, in areas such as critical care, cancer care, emergency care and nursing; four were managers. A semistructured interview schedule was developed beforehand to generate the required data in an open and flexible way. This approach allowed the researcher to opportunistically probe a particular reply or topic further, as their interests were kindled (Rubin and Rubin, 2005; Yin, 2003). In sum, a total of 12 interviews were conducted, 3 of which were conducted by the first author with employees of Manchester Foundation Trust and the remaining 9 interviews were conducted by the second author with employees of Addenbrooke's hospital, Cambridge. Table 1 provides an overview on the composition of interview partners. All interviews were conducted using videoconferencing software Zoom and Microsoft Teams.

\section{A.1. Overview of interview partners at Addenbrooke's hospital and Manchester Royal Infirmary}

\begin{tabular}{lccc}
\hline & Clinical & Nursing & Management \\
\hline Addenbrooke's hospital & 3 & 2 & 4 \\
\hline Manchester Foundation Trust & 3 & - & - \\
\hline
\end{tabular}

The recorded interviews were transcribed by help of software and then checked by the researchers. Copies of the transcripts were sent to interviewees for them to review and amend if necessary. Each interviewee was informed about the general purpose of the study and asked to sign the consent form in advance. To enable an open dialogue, all participants were promised anonymity and the opportunity to refuse any of the questions without any consequences. Four employees were not able to take part in the study due to operational pressures. The principle of saturation was followed in deciding how many interviews to conduct: Interviews were conducted until novel, additional information was no longer elicited (Glaser and Strauss, 1967).

For coding of the interview data, the qualitative data analysis software, $M A X Q D A$, was used. An initial set of categories was prepared by the second author based on observations as a research assistant at Addenbrooke's hospital since the onset of the first wave. Further codes were added as they emerged from the transcripts (Strauss and Corbin, 1998).

\section{A.2. Interview guideline}

The following line of questioning was used during interviews with employees of two hospital trusts in Manchester and Cambridge. Note that the concept of productivity was shortly described as the ratio of inputs and outputs with inputs being people, medical equipment, beds and outputs the delivery of healthcare services.

1. Can you describe which key measures were taken to manage and organise processes (e.g. clinical workflows or resource allocation) in your area of responsibility with the onset of Covid-19?

2. What was the primary goal of these measures?

3. By whom or what group was/were these changes designed and governed?

4. I would like to understand more about the time horizons of these measures. When was the first time Covid-19 measures evolved? Were policies and processes stable or were they constantly changing?

5. Which difficulties did you encounter when implementing the changes? 
6. Did some measures turn out more effective than others and why?

7. Were some policies relaxed over time and if so, what drove these relaxations?

8. What was the role of digital technology in the changes for the hospital and for patients?

9. Do you think that, in general, digital technology or IT systems helped to manage the Covid-19 crisis in a more effective way? Can you give an example?

10. From the measures we discussed, which of them do you expect to persist in the longer term?

11. In your opinion, how do you think Covid-19 has impacted productivity for Covid-19 and nonCovid-19 care at your hospital during the first wave as compared to the previous year?

12. Do you have any idea of what could help maintaining or enhancing productivity as we now face a second and maybe subsequent waves of Covid-19?

13. Is there any additional information you would like to share?

\section{A.3. Interview coding}

\begin{tabular}{|c|c|c|}
\hline Code system & Memo & Frequency \\
\hline \multirow{24}{*}{ Code System } & & 591 \\
\hline & Real estate & 13 \\
\hline & Gap analysis & 10 \\
\hline & Surge capacity & 6 \\
\hline & Intensive care surge & 2 \\
\hline & Operationalisation issues & 33 \\
\hline & Delayed communication & 5 \\
\hline & local solutions & 8 \\
\hline & Conflicting recommendations & 1 \\
\hline & Implications for patients & 9 \\
\hline & Performance indicators & 1 \\
\hline & Triage & 1 \\
\hline & Test failure & 1 \\
\hline & Shift in external demand & 30 \\
\hline & Discharges & 6 \\
\hline & Access to treatment & 1 \\
\hline & Shift in case mix & 9 \\
\hline & Lack of project management capabilities & 9 \\
\hline & System failure & 3 \\
\hline & Covid-19 prevalance & 5 \\
\hline & Transfers & 1 \\
\hline & Leadership & 11 \\
\hline & Recognition for services & 5 \\
\hline & Reflection & 1 \\
\hline
\end{tabular}


A.3. Continued

\begin{tabular}{|c|c|c|}
\hline Code system & Memo & Frequency \\
\hline & Rethinking the service & 6 \\
\hline & Potential for improvement & 1 \\
\hline & Seeking long-term approach & 1 \\
\hline & Patient-centred care & 1 \\
\hline & Adapting to change & 13 \\
\hline & Covid-19-enabled change & 1 \\
\hline & Science-based changes & 5 \\
\hline & Covid-19 over-ruling continuous improvement & 7 \\
\hline & Return to pre-Covid-19 & 2 \\
\hline & Hospital reconfiguration & 31 \\
\hline & Set-up of new units & 3 \\
\hline & Ward closure & 1 \\
\hline & Patient segregation & 9 \\
\hline & Ringfencing capacity & 4 \\
\hline & Reconfiguration & 5 \\
\hline & External governance & 12 \\
\hline & Politicisation & 1 \\
\hline & Different requirements across services & 9 \\
\hline & Different dynamics of paediatrics & 1 \\
\hline & Backlog of patients & 20 \\
\hline & Prioritisation & 10 \\
\hline & Investment in technology & 47 \\
\hline & Failure of email & 1 \\
\hline & Efficiency losses from technology & 2 \\
\hline & Face-to-face preference & 1 \\
\hline & Differences in technology & 1 \\
\hline & More capacity through technology & 2 \\
\hline & Set up of remote consultation & 4 \\
\hline & Long-term impact of technology & 8 \\
\hline & Flexibility through technology & 1 \\
\hline & Facilitation of communication through technology & 12 \\
\hline & Efficiency gains from technology & 12 \\
\hline
\end{tabular}


A.3. Continued

\begin{tabular}{|c|c|c|}
\hline \multirow[t]{2}{*}{ Code system } & Memo & Frequency \\
\hline & Constancy of change & 33 \\
\hline & Change in team and working structures & 18 \\
\hline & Tiredness of change & 7 \\
\hline & Wish for stability & 1 \\
\hline & Staff well-being & 22 \\
\hline & Buy-in of people & 6 \\
\hline & Cancellation of services & 22 \\
\hline & Continuity of care & 2 \\
\hline & Restart of services & 10 \\
\hline & Trade-offs & 22 \\
\hline & Hospital type & 3 \\
\hline & Trade-off in running different services & 14 \\
\hline & New reporting structures & 8 \\
\hline & Funding provision & 7 \\
\hline & Novelty of the disease & 38 \\
\hline & Trial and error & 2 \\
\hline & Learning processes & 8 \\
\hline & Impressions from other countries & 5 \\
\hline & Ambiguity of timelines & 4 \\
\hline & Uncertainty about future development & 7 \\
\hline & Infection control in focus & 13 \\
\hline & Donning and doffing protocols & 4 \\
\hline & Extensive fit testing requirement & 1 \\
\hline & Set up of command structure & 44 \\
\hline & Lacking responsibility and accountability & 2 \\
\hline & Hierarchical decision-making & 11 \\
\hline & Medical lead in decision-making & 6 \\
\hline & Insufficient communication across teams & 3 \\
\hline & Interdisciplinary coordination & 14 \\
\hline & Quick organisational change & 20 \\
\hline & Ease in governance processes & 5 \\
\hline & Shared responsibility & 2 \\
\hline & Shared purpose & 3 \\
\hline & Considerate spending & 2 \\
\hline
\end{tabular}


A.3. Continued

\begin{tabular}{|c|c|c|}
\hline \multirow[t]{2}{*}{ Code system } & Memo & Frequency \\
\hline & Non-availability of resources & 38 \\
\hline & Fluctuation of capacity availability & 10 \\
\hline & Increased procurement of supplies and equipment & 7 \\
\hline & Suboptimal use of available resources & 3 \\
\hline & Capacity becoming available & 5 \\
\hline & More capacity through routine testing & 3 \\
\hline & Ambiguity in resource scarcity & 2 \\
\hline & Staff re-deployment & 41 \\
\hline & Staff upskilling & 7 \\
\hline & Staff shortage & 6 \\
\hline & Change in staff rotas & 8 \\
\hline & Staff remuneration & 4 \\
\hline & Staff risk assessment & 4 \\
\hline & Modelling & 16 \\
\hline & Insufficient use of data & 5 \\
\hline & Modelling & 5 \\
\hline & External cooperation & 18 \\
\hline & Use of the independent sector & 1 \\
\hline
\end{tabular}

Cite this article: Coyle, D., Dreesbeimdiek, K. and Manley, A. (2021), 'Productivity in uk healthcare during and after the Covid-19 pandemic', National Institute Economic Review, 258, pp. 90-116. https://doi.org/10.1017/nie.2021.25 